\title{
Slow progress in the visibility of women in neurosurgery in the United States: opportunity for improvement
}

\author{
Aruna Ganju, MD, ${ }^{1}$ Uma V. Mahajan, BS, ${ }^{2,3}$ Hanna Kemeny, MD, ${ }^{1}$ H. Gregory Frankel, MD, ${ }^{1}$ and \\ Deborah L. Benzil, MD²
}

'Department of Neurological Surgery, Northwestern University, Chicago, Illinois; ${ }^{2}$ Department of Neurological Surgery, Cleveland Clinic Foundation, Cleveland; and ${ }^{3}$ Case Western Reserve University School of Medicine, Cleveland, Ohio

OBJECTIVE The goal of this study was to analyze the visibility of women within organized neurosurgery, including leadership positions, lectureships, and honored guest/award recipients at neurosurgical conferences.

METHODS A cross-sectional study was used to analyze the gender demographics within the five major national neurosurgical societies (Congress of Neurological Surgeons [CNS], American Association of Neurological Surgeons [AANS], Society of Neurological Surgeons [SNS], American Board of Neurological Surgery [ABNS], and Council of State Neurosurgical Societies [CSNS]) from 2000 to 2020. Data for top leadership positions, keynote speakers, honored guests, and invited lectureships at these neurosurgical societies were reviewed. Additionally, national neurosurgical residency match data from 2018 to 2020 were collected. For each aforementioned data point, gender was determined and confirmed via publicly available data. Data from the US News and World Report best hospitals publication for 2020 were applied for analyzing gender trends within neurosurgical residencies specifically.

RESULTS In the past 2 decades (2000-2020), top leadership positions across the neurosurgical organizations were held by 45 individuals, of whom 5 (11.1\%) were women. Spanning from 2000 to 2018, just 8.1\% (50 of 618) of guests/ honored speakers on the national neurosurgical stage of the CNS, AANS, SNS, and CSNS meetings have been female. Excluding the Louise Eisenhardt Lecture (honoring women), the percentage of female guests/honored speakers at the AANS meeting was just $5 \%$ (17 of 367). For the CNS annual meetings, $13.4 \%$ (20 of 149 ) of the speakers were women from 2000 to 2018, whereas the CSNS annual meeting data from 2001 to 2018 found that $11.9 \%$ (7 of 59) of speakers were women. From 1952 to the present, there have been no female honored guests at the CNS annual meeting. Across the residency match cycles from 2018 to 2020 , the percentages of matched applicants identifying as female have been $22.7 \%, 28.1 \%$, and, most recently, $25.3 \%$. The percentage of female residents is $28.5 \%$ (top 20 program) versus $24.3 \%$ (non-top 20 program) ( $p=0.267$ ).

CONCLUSIONS This study found that for all the data points surveyed, including leadership positions, invited lectureships at national neurosurgical meetings, and successful neurosurgical residency applicants, disproportionate female underrepresentation was evident. Consistent lack of visibility leads to a negative impact on progress in the recruitment and retention of women in neurosurgery. Visibility, mentorship, role models, and sponsorship are highly interrelated processes and are essential for meaningful progress.

https://thejns.org/doi/abs/10.3171/2020.12.FOCUS20919

KEYWORDS gender equality; leadership; neurosurgery; diversity; "manels"

$\mathrm{O}$ VER the past few decades the number of women enrolling in medical school has significantly increased, but parallel advances in the recruitment and retention of women within neurosurgery have not been realized. Underrepresentation of women in the field may be directly related to a paucity of women in leadership and senior positions within academic and organized neurosurgery. ${ }^{1}$ Across all medical and surgical specialties, women are still underrepresented in leadership positions despite decades of filling the pipeline, with a dramatically increasing proportion of women entering medicine since the 1970s. ${ }^{2}$ Within academic medicine, women hold just $22 \%$ of full professorships, $18 \%$ of department chairs, and $17 \%$ of medical school dean positions. ${ }^{3}$ Despite some marginal improvement, within neurosurgery the numbers are even more distressing. In 2016, more than 50 years after

ABBREVIATIONS AANS = American Association of Neurological Surgeons; ABNS = American Board of Neurological Surgery; CNS = Congress of Neurological Surgeons; CSNS = Council of State Neurosurgical Societies; SNS = Society of Neurological Surgeons; WINS = Women in Neurosurgery.

SUBMITTED October 29, 2020. ACCEPTED December 16, 2020.

INCLUDE WHEN CITING DOI: 10.3171/2020.12.FOCUS20919. 
the first women reached ABNS certification, there was only 1 female department chair (there have now been 5), 3 vice chairs, and 7 residency program directors. There are also other concerning disparities. Between 2000 and 2009 , the attrition rate for female neurosurgery residents was $17 \%$ compared to $5.3 \%$ for males, although this was an improvement from the $25 \%$ attrition rate for female trainees during the previous 10 -year period. ${ }^{4}$ In total, women comprise just $16.3 \%$ of residents, $6.1 \%$ of boardcertified neurosurgeons, and $4 \%$ of full professorships. ${ }^{5}$ While these numbers do represent an improvement, they still fall short of the goals laid out by the Women in Neurosurgery (WINS) white paper from 2008, which called for a $20 \%$ female enrollment rate in neurosurgical residencies by $2012 .^{6}$

Studies within the financial world have demonstrated that companies with higher proportions of female representation on company boards and in executive positions have continually outperformed their competitors with respect to risk management, operating results, return on equity, and stock growth. ${ }^{7}$ Despite this compelling evidence, the healthcare sector has fallen behind with respect to females in leadership positions. Visibility of diversity within leadership positions, award winners, invited lectureships, and honored guest speakers within medical specialty organizations and conferences has been demonstrated to be critical in achieving progress. Studies analyzing gender equality in leadership positions across 39 medical subspecialty societies during the decade from 2008 to 2017 found that men served as society presidents in $82.6 \%$ $(322 / 390)$ of the total years, while 10 of the 39 societies had zero years of female presidential leaders during that time frame. ${ }^{8}$ Contemporary analysis of 27 medical specialty conferences found that only $25 \%$ (246 of 984) of invited speakers were women. ${ }^{9}$ Similar underrepresentation was confirmed across five different regions in the world in a study that found that women accounted for only 7064 of 23,440 (30.1\%) invited speakers. ${ }^{10}$ These "manels" are concerning because they limit diverse perspectives and run the risk of sending the wrong message to younger female physicians and scientists. Understanding the magnitude of the problem, in 2019 Francis Collins, the director of the National Institutes of Health, published a statement conveying that he would no longer attend conferences that do not demonstrate an attentiveness to equal representation. ${ }^{11}$

Aside from these serious concerns, "manels" and failure of diverse leadership naturally limit career advancement for females because benchmarks such as keynote or invited lectureships, invited conference presentations, and visiting professor grand rounds are considered indicators of national or international renown and have been shown to be critical metrics for promotion in academia., ${ }^{3,12}$ Likewise, the lack of female representation in these areas makes it difficult for female medical students, residents, and junior faculty to identify potential mentors or sponsors. Both mentorship and sponsorship have repeatedly been shown to play a significant role in career advancement. $3,13,14$

Neurosurgery has traditionally been male dominated, but since 1962 it has begun to include women. The growth of women in neurosurgery was slow initially but has been gaining momentum over the past few decades, including the election of Shelly Timmons, MD, PhD, as the first female neurosurgeon to serve as president of the American Association of Neurological Surgeons (AANS). Despite the modest improvements in our field, recruitment, retention, and promotion of female neurosurgeons remain a considerable challenge and many female neurosurgeons feel the burden of a "glass ceiling." Analysis of the visibility of women within organized neurosurgery including leadership positions, lectureships, and honored guest/ award recipients at neurosurgical conferences is the focus of this paper. Understanding factors such as this that can impede the progress of women will be important for continued progress.

\section{Methods}

To analyze trends in organized neurosurgery leadership, data were gathered on leaders in five major neurosurgical organizations: Congress of Neurological Surgeons (CNS), AANS, Society of Neurological Surgeons (SNS), American Board of Neurological Surgery (ABNS), and Council of State Neurosurgical Societies (CSNS). The gender of the top executive position (president in CNS, AANS, and SNS, and chair of ABNS and CSNS) for each term over the past 2 decades (2000-2020) was recorded. For the current term, we collected gender data in regard to all leadership positions (e.g., committees, subcommittees) in the five organizations.

To analyze trends in speakers in neurosurgery, the gender of invited speakers over the past 2 decades at the national AANS, CNS, and CSNS meetings was recorded. For the annual AANS meetings, we looked at data provided by the AANS on invited speakers in keynote lectures in the 2003-2018 time frame. For the annual CNS meetings, we studied gender data in regard to invited speakers in keynote lectures from the years 2000 to 2018. The CNS Honored Guest lectureship data were collected from the years 1952 to 2020. For CSNS meetings, we looked at invited speakers, including both award winners (2003-2018) and luncheon speakers (2001-2018). For SNS meetings, keynote speaker awardees data were collected.

In order to complete the picture on gender trends within the field, data were collected in regard to the gender distribution of successful neurosurgical applicants in the National Residency Matching Program over the course of 3 years: 2018-2020. Each individual neurosurgical residency's program website was searched to identify current cohorts within each residency class. In an effort to provide reliability and reproducibility of data, neurosurgical programs that did not have up-to-date residency information were not included. Resident postgraduate year level and names were confirmed when applicable with the AANS 2020 Neurosurgery Residency Matches self-reported website..$^{15}$ Gender was determined and confirmed using publicly available data. Neurosurgical programs in which residents across all 3 years in question were not clearly listed on program websites were excluded.

To analyze trends within all identified programs meeting the inclusion criteria in comparison to the top 20-rat- 
TABLE 1. Top leadership positions in organized neurosurgery

\begin{tabular}{|c|c|c|c|c|c|}
\hline Year & CNS & AANS & SNS & ABNS & CSNS* $^{*}$ \\
\hline $\begin{array}{l}\text { Pre-2000 totals } \\
\text { (women/all) }\end{array}$ & $0 / 49$ & $1 / 68 \dagger$ & $0 / 80$ & $0 / 41$ & $0 / 8$ \\
\hline 2000-2001 & Daniel L. Barrow & Stewart B. Dunsker & Howard Eisenberg & Steven L. Giannotta & Lyal Leibrock \\
\hline 2001-2002 & Issam A. Awad & Stan Pelofsky & Martin H. Weiss & Dennis D. Spencer & \\
\hline $2002-2003$ & Stephen M. Papadopoulos & Roberto C. Heros & Robert A. Ratcheson & David G. Piepgras & David Jimenez \\
\hline $2003-2004$ & Mark N. Hadley & A. John Popp & David Piepgras & Arthur L. Day & \\
\hline 2004-2005 & Vincent C. Traynelis & Robert A. Ratcheson & Philip Weinstein & Ralph G. Dacey Jr. & Frederick Boop \\
\hline $2005-2006$ & Nelson M. Oyesiku & Fremont P. Wirth Jr. & Charles Hodge & William F. Chandler & \\
\hline $2006-2007$ & Richard G. Ellenbogen & Donald O. Quest & A. John Popp & Robert A. Solomon & Fernando Diaz \\
\hline $2007-2008$ & Douglas Kondziolka & Jon H. Robertson & Dennis Spencer & H. Hunt Batjer & \\
\hline $2008-2009$ & Anthony L. Asher & James R. Bean & Edward H. Oldfield & M. Sean Grady & Gary Bloomgarden \\
\hline 2009-2010 & P. David Adelson & Troy M. Tippett & Robert Dempsey & Warren R. Selman & \\
\hline $2010-2011$ & Gerald E. Rodts Jr. & James T. Rutka & Allan Friedman & Charles L. Branch & William Bingaman \\
\hline 2011-2012 & Christopher C. Getch & Paul C. McCormick & Arthur L. Day & Daniel L. Barrow & \\
\hline 2012-2013 & Christopher E. Wolfla & Mitchel S. Berger & Ralph G. Dacey Jr. & Nelson M. Oyesiku & Deborah Benzil \\
\hline 2013-2014 & Ali R. Rezai & William T. Couldwell & Kim J. Burchiel & David W. Roberts & \\
\hline 2014-2015 & Daniel K. Resnick & Robert E. Harbaugh & H. Hunt Batjer & Fredric Meyer & Mark Linskey \\
\hline 2015-2016 & Nathan R. Selden & H. Hunt Batjer & Robert E. Harbaugh & Jeff Bruce & \\
\hline 2016-2017 & Russell R. Lonser & Frederick A. Boop & Alan Cohen & Christopher Shaffrey & Ann Stroink \\
\hline 2017-2018 & Alan M. Scarrow & Alex B. Valadka & Nicholas Barbaro & B. Gregory Thompson & \\
\hline 2018-2019 & Ashwini D. Sharan & Shelly D. Timmons & Daniel L. Barrow & Richard G. Ellenbogen & Joshua Rosenow \\
\hline 2019-2020 & Ganesh Rao & Christopher I. Shaffrey & Karin M. Muraszko & Linda Liau & \\
\hline $2020-2021$ & Steven N. Kalkanis & John A. Wilson & M. Sean Grady & Carl B. Heilman & Michael Steinmetz \\
\hline
\end{tabular}

Boldface type indicates female leaders.

* CSNS chairperson terms are 2 years, starting and ending in odd-numbered years

† Louise Eisenhardt, MD, was a neuropathologist.

ed neurosurgical programs by the US News and World Report,$^{16}$ we compared the percentage of women in academic programs who have been rated in the top 20 by US News and World Report to other academic programs, and performed the 2-proportion z-statistic 2-tailed test.

\section{Results}

\section{Leadership}

In the 2 decades spanning 2000-2020, the five neurosurgical organizations had a total of 45 individuals occupying the top leadership position; of these, 5 (11.1\%) individuals were female. Specifically, Deborah L. Benzil, MD, and Ann Stroink, MD, were elected chair of the CSNS in 2011-2013 and 2015-2017, respectively (i.e., 2/11 [18\%]); Shelly Timmons, $\mathrm{MD}, \mathrm{PhD}$, was president of the AANS in 2018-2019 (1/21 [5\%]); Karin Muraszko, MD, was president of the SNS in 2019-2020 (1/21 [5\%]); and Linda Liau, MD, was president of the ABNS in 2019-2020 (1/21 [5\%]) (Table 1, Fig. 1). Prior to 2000 , only $0.41 \%$ (1/246) of top leadership positions were held by women; Louise Eisenhardt, MD, a neuropathologist, was president of the AANS from 1938 to 1939.

In the current leadership term, across the five organizations, $19.2 \%$ (15 of 78 individuals) of executive committee positions and $16.9 \%$ (76 of 450) of subcommittee positions are occupied by women (Table 2, Fig. 1).
Among AANS board of director members since 1990, $6.7 \%$ (12 of 178 individuals) were women. Among CSNS officers and standing committees since 1990, 8.8\% (25 of 285 individuals) were women.

\section{Speakers at Premier National Neurosurgery Meetings}

Over the 2 decades spanning from 2000 to 2018, just $8.1 \%$ of speakers on the national neurosurgical stage of the CNS, AANS, SNS, and CSNS meetings have been female (Table 2, Fig. 2).

Breakdown by meeting reveals that at the AANS annual meetings in the analysis, $8 \%$ (29 of 379) of the speakers were women. When the Louise Eisenhardt Lecture (which specifically honors women who embody the dedication of Dr. Eisenhardt) is excluded, the percentage of female speakers decreases to $5 \%$ (17 of 367).

At the CNS annual meetings, $13.4 \%$ (20 of 149) of the speakers were women from 2000 to 2018 . Additionally, on review of the 2018 Scientific Program, 16.9\% (79 of 468) of faculty were women (Fig. 2). Among the CNS Clinical Fellowship Award winners from 1987 to 2013, 11.9\% (16 of 134 recipients) were women. Notably, at the CNS meeting, the Honored Guest lecture is the only invited lecture for which the recipient is traditionally a neurosurgeon. In a 67-year period, from 1952 to 2020,0 of 71 honored guests were women. 


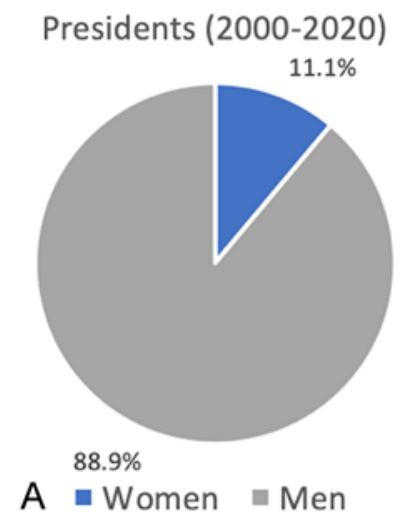

Executive Committees (2020)

Subcommittees (2020)
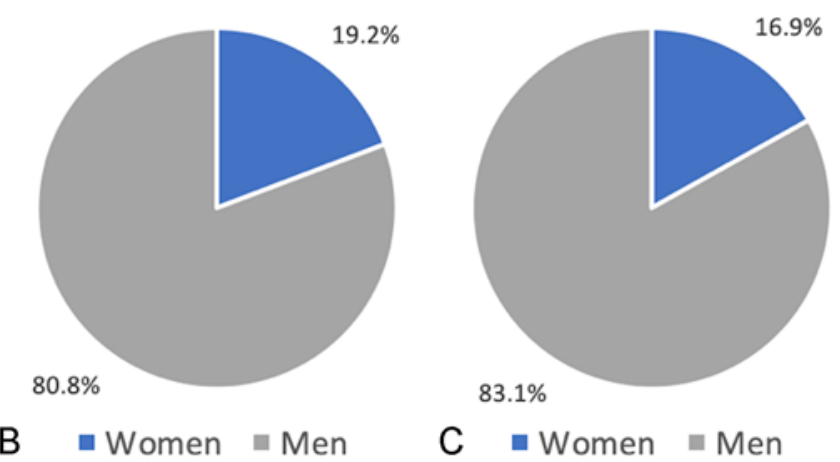

FIG. 1. A: Presidents (or comparable top position) in the past 2 decades. B: Current executive committees (or comparable top board). C: Current subcommittees that are WINS organizations (i.e., CNS, AANS, SNS, ABNS, CSNS).

Review of the CSNS annual meeting data from 2001 to 2018 found that $11.9 \%$ (7 of 59) of speakers were women (Table 2). Further analysis of these talks revealed that $13.0 \%$ (3 of 23) of award winners (2003-2018) and 11.1\% (4 of 36) of luncheon speakers (2001-2018) were women.

At the SNS meetings, a total of $14.0 \%$ (6 of 43) of keynote speakers were women.

\section{Recent Residency Match}

Across the past 3 years, there were a total of 105 programs that had complete data available. Of the 673 residents reported, 171 (25.4\%) were female and 502 (74.6\%) were male. This overall percentage appears relatively stable across the past 3 years, ranging from $22.7 \%$ to $28.1 \%$, and is more than thrice the percentage of female ABNScertified neurosurgeons over the same period (Figs. 3 and 4). When programs are separated by US News and World Report rankings (top 20 program vs non-top 20 program), the percentage of female residents is $28.5 \%$ (top 20 program) versus $24.3 \%$ (non-top 20 program) ( $\mathrm{p}=0.267$, 2-tailed test) (Fig. 5).

\section{Discussion}

It has been more than 60 years since the first woman achieved ABNS certification, and it has been 30 years since the establishment of Women in Neurosurgery (WINS) decades of slow progress. In this study, we analyzed the recent visibility of females in the field of neurological surgery decades after their entry into this male-dominated specialty. The disproportionate female underrepresentation within the field is one seen in many other industries; in the science, technology, engineering, mathematics, and medicine (STEMM) fields; and in academic medicine. Unsurprisingly, for all the data points surveyed in this study, including leadership positions in the major neurosurgical organizations, invited lectureships at national neurosurgical meetings, and successful neurosurgical residency applicants, disproportionate underrepresentation was found. Unfortunately, this consistent lack of visibility suggests the potential for a worrisome domino effect for progress in the recruitment and retention of women in neurosurgery. Visibility, mentorship, role models, and sponsorship are highly interrelated processes and are essential for meaningful progress.

Although women account for more than $50 \%$ of US medical students, as of 2016, only $16.3 \%$ of neurosurgery residents and $6.1 \%$ of ABNS-certified surgeons are female. ${ }^{5}$ Tracking the career paths of women in neurosurgery yields depressing statistics-females are underrepresented in the higher echelons of the field, including academic/institutional rank, organizational leadership,

TABLE 2. Female gender percentage of executive committee members, subcommittee members, and conference speakers/honored guests

\begin{tabular}{cccc}
\hline Organization & Executive Committee & Subcommittees & \multicolumn{1}{c}{ Speakers } \\
\hline CNS & $30.8 \%(8$ of 26$)$ & $13.5 \%(22$ of 163$)$ & $13.4 \%(20$ of 149$)$ \\
\hline AANS & $10 \%(1$ of 10$)$ & $21.8 \%(26$ of 119$)$ & $5 \%(17 \text { of } 367)^{*}$ \\
\hline SNS & $20 \%(4$ of 20$)$ & $16.5 \%(23$ of 139$)$ & $14.0 \%(6$ of 43$)$ \\
\hline ABNS & $13.3 \%(2$ of 15$)$ & NA & NA \\
\hline CSNS & $0 \%(0$ of 7$)$ & $17.2 \%(5$ of 29$)$ & $11.9 \%(7$ of 59$)$ \\
\hline Overall & $19.2 \%(15$ of 78$)$ & $16.9 \%(76$ of 450$)$ & $8.1 \%(50$ of 618$)$ \\
\hline
\end{tabular}

$\mathrm{NA}=$ not applicable.

Committee data collected represent positions held during the current term (2020) in organized neurosurgery (CNS,

AANS, SNS, ABNS, CSNS). Speaker data represent national meetings from 2000 to 2018.

* Louise Eisenhardt Lecture not included. 


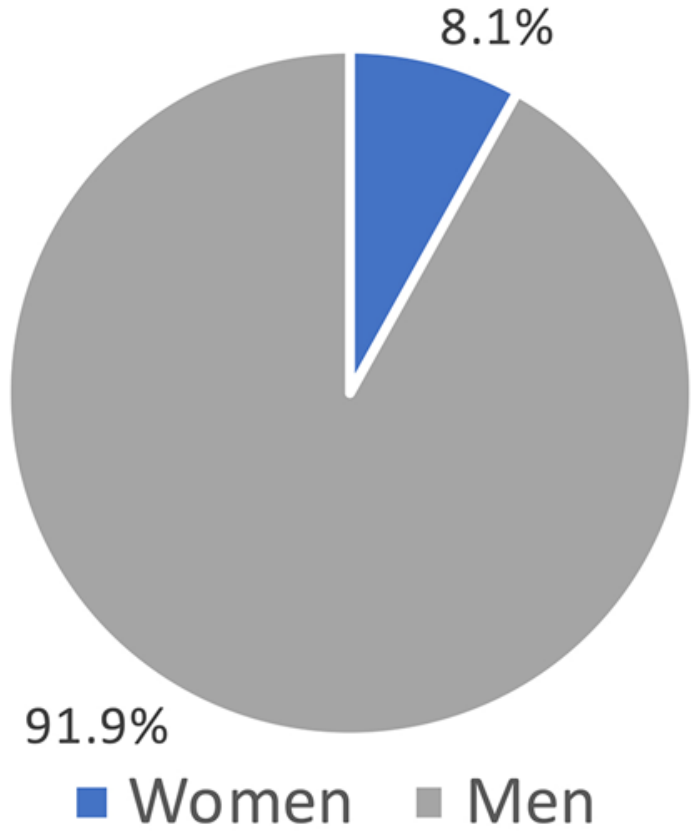

FIG. 2. Gender makeup of conference speakers at national meetings (i.e., CNS, AANS, SNS, ABNS, CSNS) in 2000-2018.

and invited plenary talks on a national stage. This issue becomes compounded at each step along the ladder to the top. Although there are innumerable variables that influence an individual's career path in medicine, both mentorship and sponsorship have been identified as factors that can advance a physician's career. In recent studies, however, the latter has been recognized as being more critical in the professional advancement of women. ${ }^{14,17}$ Sponsorship necessitates the presence of a person who holds a position of authority and influence within an organization to advocate on behalf of another. Sponsorship has been shown to be critical in advancement to high-level leadership positions. The paucity of women on the national neurosurgical stage, whether as leaders of professional organizations or as invited speakers, limits the potential opportunities for sponsorship.

As a result, women have a more difficult road to professional advancement at the institutional and departmental level, with fewer of them achieving the rank of associate or full professor, or reaching those achievements more slowly; this paucity of female role models at the level of academic departments then results in less diversity to inspire current medical students. The cycle of underrepresentation of women within neurological surgery continues in perpetuity ... . or does it?

The 2008 white paper on the future of women in neurosurgery leaned on organized neurosurgery to achieve a $20 \%$ female complement within neurosurgical training programs and a $20 \%$ female faculty composition by 2012.6 Did neurosurgery achieve that goal? The match results for the three most recent cycles (2017-2018, 2018-2019, 2019-2020) suggest that the field has finally exceeded that target-with $22.7 \%, 28.1 \%$, and, most recently, $25.3 \%$ of matched applicants identifying as female. This number represents an increase from the 2016 match in which $17 \%$ of matched applicants were women. ${ }^{17}$ Over this same period of time, the percentage of ABNS-certified female neurosurgeons has remained relatively static, ranging from $6.3 \%$ to $6.8 \% .^{18}$

There is now extensive assessment of the role of society leadership as it pertains to female practitioners within medicine and other specialties, describing microinequities that lead to the invisibility and marginalization of women. ${ }^{8,9}$ In order for academic medicine to recruit and retain women within its ranks, midcareer physicians need opportunities such as speaking invitations at national conferences and academic grand rounds. Review of the available data for the major neurosurgical organizations reveals a long history of underrepresentation of women in these
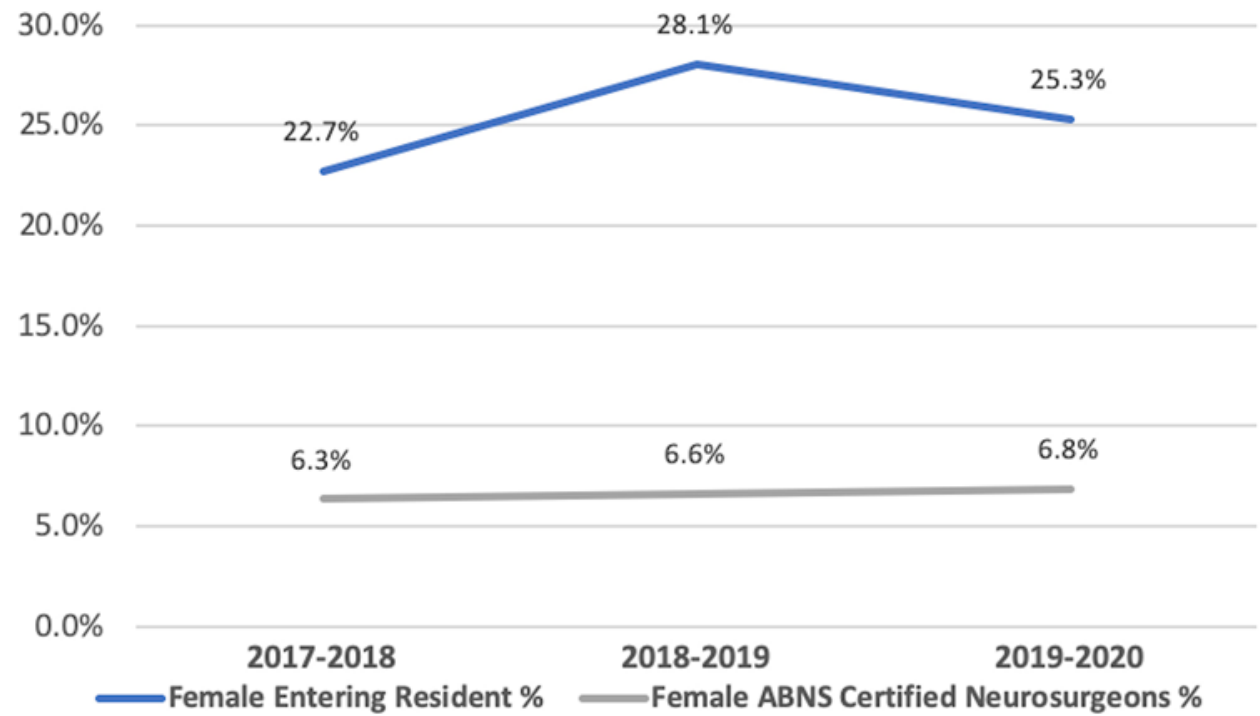

FIG. 3. Percentages of female residents entering neurosurgery and female ABNS-certified neurosurgeons in the past 3 years. 


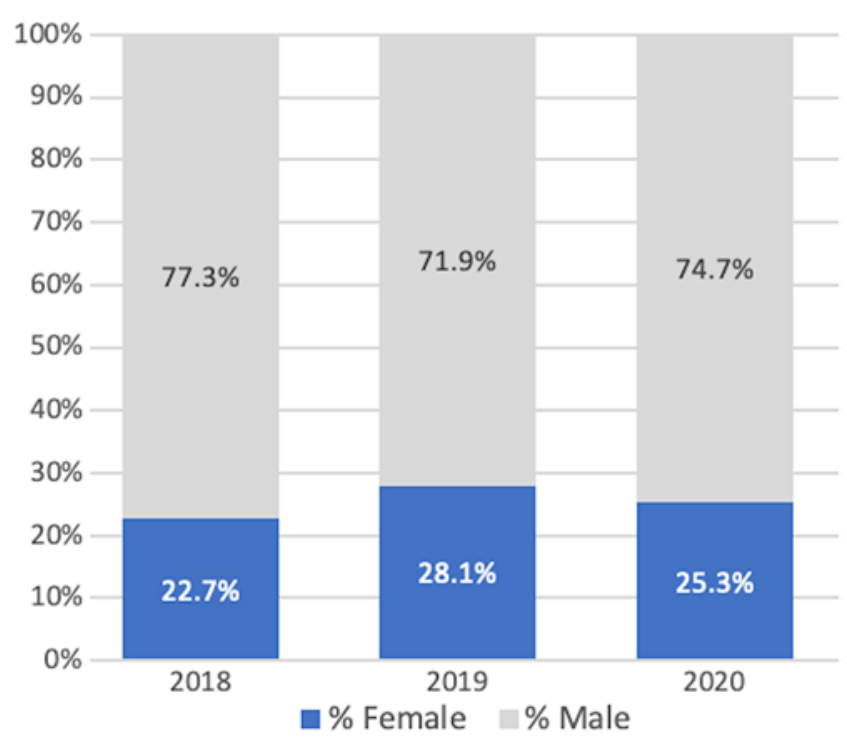

FIG. 4. Gender distribution trends from 2018 to 2020 , analyzed by individual year.

areas. Although it could be argued that the pipeline for women neurosurgeons is just not long enough to achieve significant recognition and representation, the paucity of females extends beyond neurosurgery, where the same imbalance is less pronounced. However, some glass ceilings are showing cracks. Over the 2 decades examined in this paper, $11.1 \%$ of top leadership positions in five national neurosurgical organizations were held by women; four of these occurred in the 4 years since 2016. During the current term, $19.2 \%$ and $16.9 \%$ of board/executive committee and other major committee positions in these five organizations are held by women.

Invited lectureships or speaking engagements on a national neurosurgical stage are equally important for visibility within medical societies. The CNS Honored Guest is the only lectureship that features a neurosurgeon, who delivers three plenary session talks; in the 69 years of the award's existence, $100 \%$ of those chosen have been men. Traditionally, the honored guest is selected by the CNS president; it represents an opportunity for the president to publicly recognize a mentor or sponsor. Such cronyism only leads to perpetuation of the cycle of homogeneity. If the field and its organizations want to diversify and evolve, alternate objective criteria should be used in selecting the awardees of named lectureships. As advocated by Dr. Francis Collins, diverse and heterogeneous representation in all forums is important and must be a component in decision-making for annual program and scientific planning committees for all our neurosurgical organizations. Such an approach recognizes that diversity leads to innovation and progress. The business world has long recognized the role of diversity in an organization's success; benefits include innovation, increased productivity, and strength. In this regard, gender diversity is invaluable. ${ }^{19,20}$ A gender gap in authorship of papers has also been identified as another challenge to visibility ${ }^{18}$ Recently, a comprehensive multipronged corrective approach to the gender discrepancy

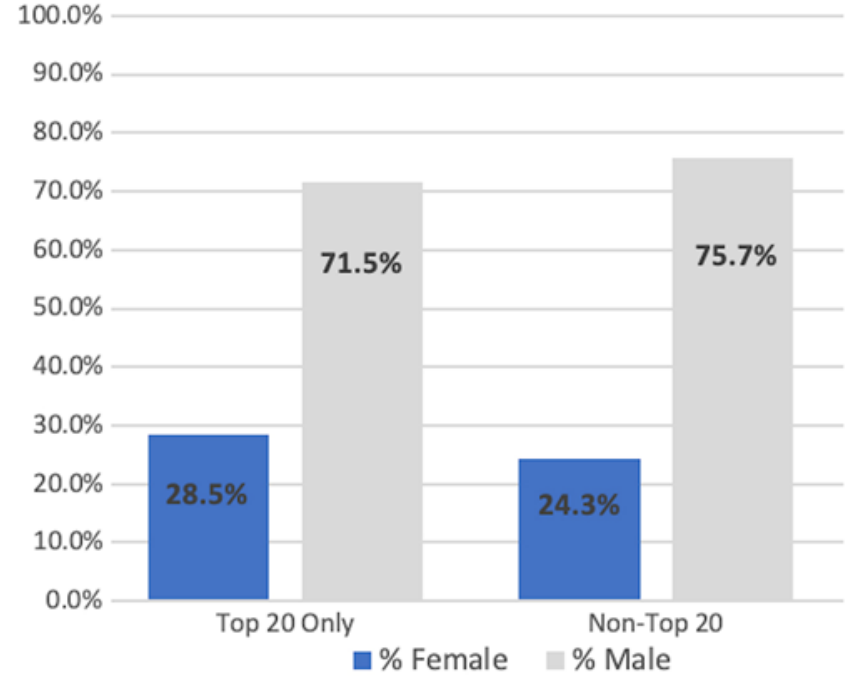

FIG. 5. Percentage of females in top 20-rated residency programs compared to non-top 20-rated residency programs (2018-2020). Of note, residency match data were collected from matches in 2018-2020 and the top 20 rating was based on US News and World Report data from 2020.

within our field was outlined: these recommendations included routine and consistent tracking of gender metrics, commitment to increased female representation at all academic ranks, pledge to inclusion at the podium, and increased societal leadership representation. ${ }^{4}$

The year 2020 has been tumultuous, and as a result the world has seen the consequence of systemic conformity and exclusion. Data points such as education, employment, salary, access to healthcare, and medical comorbidities have been revealed as leading to considerably different risks and outcomes related to the COVID-19 pandemic as well as the economic impact of the same. The interrelatedness and cause-effect relationship among these parameters cannot be ignored. In addition, social media efforts including \#ILookLikeaSurgeon, \#MeToo, and \#SheLeadsHealthcare brought attention to considerable gender disparity across fields as well as the significant impact of both covert and overt methods of discrimination and harassment of one group by another. Healthcare revealed itself to have been slow to critically clean its own house.

\section{Conclusions}

This study found that for all the data points surveyed, including leadership positions, invited lectureships at national neurosurgical meetings, and successful neurosurgical residency applicants, disproportionate female underrepresentation was found. Consistent lack of visibility leads to a negative impact on progress in the recruitment and retention of women in neurosurgery. Visibility, mentorship, role models, and sponsorship are highly interrelated processes and are essential for meaningful progress.

The Journal of Neurosurgery Publishing Group, through its publication Neurosurgical Focus, deserves credit for proactively choosing to devote the March 2021 issue to "International women leaders in neurosurgery: 
past, present, and future." This attention to investigating the field's history and leadership recognizes an important gap in our literature as well as acknowledges that where we come from informs who we will become. Knowing that diversity and inclusion are inherent to successful evolution, it is our hope that this issue of Neurosurgical Focus will inspire our field's leaders to recognize the need to constantly advocate for and sponsor the participation of all who share our passion for the field.

\section{References}

1. Odell T, Toor H, Takayanagi A, et al. Gender disparity in academic neurosurgery. Cureus. 2019;11(5):e4628.

2. Zhuge Y, Kaufman J, Simeone DM, et al. Is there still a glass ceiling for women in academic surgery? Ann Surg. 2011; 253(4):637-643.

3. Lewiss RE, Silver JK, Bernstein CA, et al. Is academic medicine making mid-career women physicians invisible? $J$ Womens Health (Larchmt). 2020;29(2):187-192.

4. Abosch A, Rutka JT. Women in neurosurgery: inequality redux. J Neurosurg. 2018;129(2):277-281.

5. Renfrow JJ, Rodriguez A, Wilson TA, et al. Tracking career paths of women in neurosurgery. Neurosurgery. 2018;82(4): 576-582.

6. WINS White Paper Committee; Benzil DL, Abosch A, Germano I, et al. The future of neurosurgery: a white paper on the recruitment and retention of women in neurosurgery. $J$ Neurosurg. 2008;109(3):378-386.

7. Johns ML. Breaking the glass ceiling: structural, cultural, and organizational barriers preventing women from achieving senior and executive positions. Perspect Health Inf Manag. 2013;10:1e.

8. Silver JK, Ghalib R, Poorman JA, et al. Analysis of gender equity in leadership of physician-focused medical specialty societies, 2008-2017. JAMA Intern Med. 2019;179(3):433435.

9. Larson AR, Sharkey KM, Poorman JA, et al. Representation of women among invited speakers at medical specialty conferences. J Womens Health (Larchmt). 2020;29(4):550560.

10. Arora A, Kaur Y, Dossa F, et al. Proportion of female speakers at academic medical conferences across multiple specialties and regions. JAMA Netw Open. 2020;3(9): e2018127.

11. Collins FS. Time to end the manel tradition. The NIH Director. National Institutes of Health. Published online June 12, 2019. Accessed January 20, 2021. https://www.nih.gov/ about-nih/who-we-are/nih-director/statements/time-endmanel-tradition

12. Ioannidis JPA. Are medical conferences useful? And for whom? JAMA. 2012;307(12):1257-1258.
13. Ayyala MS, Skarupski K, Bodurtha JN, et al. Mentorship is not enough: exploring sponsorship and its role in career advancement in academic medicine. Acad Med. 2019;94(1): 94-100.

14. Travis EL, Doty L, Helitzer DL. Sponsorship: a path to the academic medicine C-suite for women faculty? Acad Med. 2013;88(10):1414-1417.

15. 2020 neurosurgical residency matches. American Association of Neurological Surgeons. Accessed January. https://www. aans.org/en/Trainees/Medical-Students/NeurosurgicalResidency-Matches

16. Best hospitals for neurology \& neurosurgery. US News and World Report. Accessed January 20, 2021. https:// health.usnews.com/best-hospitals/rankings/neurology-andneurosurgery

17. Renfrow JJ, Rodriguez A, Liu A, et al. Positive trends in neurosurgery enrollment and attrition: analysis of the 20002009 female neurosurgery resident cohort. J Neurosurg. 2016;124(3):834-839.

18. Mahajan UV, Wadhwa H, Fatemi P, et al. Does doubleblinded peer review impact gender authorship trends? An evaluation of two leading neurosurgical journals from 20102019. J Neurosurg. Published online November 13, 2020. doi: 10.3171/2020.6.JNS20902

19. Hunt V, Layton D, Prince S. Why diversity matters. McKinsey \& Company. Published online January 1, 2015. Accessed January 20, 2021. https://www.mckinsey.com/ business-functions/organization/our-insights/why-diversitymatters

20. Rock D, Grant H. Why diverse teams are smarter. Harvard Business Review. Published online November 4, 2016. Accessed January 20, 2021. https://hbr.org/2016/11/whydiverse-teams-are-smarter

\section{Disclosures}

The authors report no conflict of interest concerning the materials or methods used in this study or the findings specified in this paper.

\section{Author Contributions}

Conception and design: Ganju. Acquisition of data: Ganju, Mahajan, Kemeny. Analysis and interpretation of data: all authors. Drafting the article: all authors. Critically revising the article: all authors. Reviewed submitted version of manuscript: all authors. Approved the final version of the manuscript on behalf of all authors: Ganju. Statistical analysis: Mahajan, Kemeny. Study supervision: Benzil.

\section{Correspondence}

Aruna Ganju: Northwestern Memorial Hospital, Chicago, IL. aganju@nm.org. 